\title{
Usefulness of two independent histopathological classifications of tumor regression in patients with rectal cancer submitted to hyperfractionated pre-operative radiotherapy
}

\author{
Łukasz Liszka, Ewa Zielińska-Pająk, Jacek Pająk, Dariusz Gołka, Jacek Starzewski, Zbigniew Lorenc
}

Łukasz Liszka, Ewa Zielińska-Pająk, Jacek Pająk, Department of Pathology, Medical University of Silesia, ul. Medyków 14, Katowice 40-754, Poland

Dariusz Gołka, Department of Pathology, Victoria Hospital, Whinney Heys Road, Blackpool FY3 8NR, United Kingdom Jacek Starzewski, Zbigniew Lorenc, Department of General and Colorectal Surgery, Medical University of Silesia, Plac Medyków 1, Sosnowiec 41-200, Poland

Correspondence to: Jacek Pająk, Department of Pathology, Medical University of Silesia, ul. Medyków 14, Katowice 40-754, Poland.makpaj@o2.pl

Telephone: +48-32-2525080 Fax: +48-32-2525080

Received: 2006-10-03 Accepted: 2006-12-11

\begin{abstract}
AIM: To assess the usefulness of two independent histopathological classifications of rectal cancer regression following neo-adjuvant therapy.
\end{abstract}

METHODS: Forty patients at the initial stage cT3NxM0 submitted to preoperative radiotherapy (42 Gy during $18 \mathrm{~d}$ ) and then to radical surgical treatment. The relationship between "T-downstaging" versus regressive changes expressed by tumor regression grade (TRG 1-5) and Nasierowska-Guttmejer classification (NG 1-3) was studied as well as the relationship between TRG and NG versus local tumor stage ypT and lymph nodes status, ypN.

RESULTS: Complete regression (ypT0, TRG 1) was found in one patient. "T-downstaging" was observed in $11(27.5 \%)$ patients. There was a weak statistical significance of the relationship between "T-downstaging" and TRG staging and NG stage. Patients with ypT1 were diagnosed as TRG 2-3 while those with ypT3 as TRG5. No lymph node metastases were found in patients with TRG 1-2. None of the patients without lymph node metastases were diagnosed as TRG 5 . Patients in the ypT1 stage were NG 1-2. No lymph node metastases were found in NG 1 . There was a significant correlation between TRG and NG.

CONCLUSION: Histopathological classifications may be useful in the monitoring of the effects of hyperfractionated preoperative radiotherapy in patients with rectal cancer at the stage of cT3NxM0. There is no unequivocal relationship between "T-downstaging" and TRG and NG. There is some concordance in the assessment of lymph node status with ypT, TRG and NG. TRG and NG are of limited value for the risk assessment of the lymph node involvement.

(c) 2007 The WJG Press. All rights reserved.

Key words: Rectal cancer; Adenocarcinoma; Neoadjuvant therapy; Preoperative radiotherapy; Neoplasm staging

Liszka Ł, Zielińska-Pajakk E, Pająk J, Gołka D, Starzewski J, Lorenc Z. Usefulness of two independent histopathological classifications of tumor regression in patients with rectal cancer submitted to hyperfractionated pre-operative radiotherapy. World J Gastroenterol 2007; 13(4): 515-524

http://www.wjgnet.com/1007-9327/13/515.asp

\section{INTRODUCTION}

Colorectal cancer is the third most common malignancy diagnosed in the USA ${ }^{[1]}$. The estimated colorectal cancer mortality in the USA in 2006 is $55170^{[2]}$. The primary treatment method for rectal cancer is surgery, namely anterior rectal resection, abdomino-perineal resection or local excision ${ }^{[3-6]}$. Preoperative radiotherapy and radiochemotherapy play an increasing role in the treatment of rectal cancer ${ }^{[7-13]}$. The effectiveness of neo-adjuvant therapy may be assessed and monitored by means of longterm survival follow up, incidence of local recurrence, estimation of the percentage of patients with primary high stage tumor suitable for radical surgery, estimation of the percentage of patients suitable for sphincter-saving surgery or by monitoring the tumor stage using visualizing diagnostic methods ${ }^{[14,15]}$. Transrectal ultrasound (TRUS) is a useful method for the assessment of the local tumor stage and the regional lymph node status prior to neo-adjuvant therapy ${ }^{[3,4,6,16]}$. Basing on TRUS and histopathological examination one can define the tumor regression parameter "T-downstaging". Lower ypT parameter value (local tumor stage assessed by the pathologist in surgical specimen following neo-adjuvant therapy) than uT (local 
tumor stage assessed by surgeon with use of TRUS prior to neo-adjuvant therapy) is considered an evidence of tumor regression. The value of ypT parameter equal or higher than $\mathrm{u} T$ indicates lack of tumor regression ${ }^{[11,14,17-21]}$.

This parameter may also be applied to the regression of metastatic regional lymph nodes in rectal cancer, "N-downstaging",[17,20,22-26].

Preoperative radiotherapy and radiochemotherapy evokes a range of morphological changes in the microscopic picture of rectal cancer including increased tumor necrosis, cellular and nuclear atypia, endocrine differentiation of tumor cells, increased stromal fibrosis, quantitative and qualitative changes of the stromal inflammatory exudates, formation of mucin pools, surface ulceration, peritumoral eosinophilic infiltrate, dysplastic and adenomatous changes (high-grade dysplasia, and lowgrade adenoma component in the intestinal mucosa $)^{[5,27,28]}$. Several histopathological classifications of rectal carcinoma response to neo-adjuvant therapy have been proposed $^{[5,20,29-33]}$. However, none of these classifications is used in routine histopathological diagnostics. This results from the fact that macro- and microscopic changes within the tumor structure and surrounding tissues are not a specific response to ionizing radiation but also may result from the non-specific inflammation, hormonal therapy and local immune reaction ${ }^{[5,7]}$. Tumor regression grade (TRG) is a semi-quantitative parameter describing a relative proportion of residual tumor and stromal fibrosis. It is regarded a useful parameter for the assessment of histopathological changes in tumor following neoadjuvant therapy ${ }^{[14,18,19,21,22,29,34-38]}$. There are five grades of cancer response to treatment in TRG staging, ranging from TRG 1-no residual cancer cells in the intestinal wall, replaced by fibrous tissue, through TRG 2-presence of occasional residual cancer cells, scattered in fibrous stroma, TRG 3-fibrosis dominating over residual cancer, TRG 4-residual cancer outgrowing fibrosis, to TRG 5-no tumor response or regression, no fibrosis with extensive residual cancer ${ }^{[29]}$. Another classification, proposed by Nasierowska-Guttmejer (NG) distinguishes three degrees of cancer response to neo-adjuvant therapy depending on the intensity of the morphological changes. At present one should assess cancer cell degeneration (no cancer cells, high, moderate and low-grade degeneration), mucus pools (present or absent) and necrosis (absent, $\leqslant 50 \%$ cancer tissue, $>50 \%$ cancer tissue). Point scores are designated to each parameter of tumor response to neo-adjuvant therapy and then are summarized ${ }^{[5]}$.

Some authors believe that "T-downstaging" does not precisely reflect cancer regression following neo-adjuvant therapy. They state that residual cancer has a form of rather small foci surrounded by fibrous tissue and they are localized in all layers of the rectal wall. Such a deep localization results in diagnosis of high tumor stage despite a good response to radiotherapy. This phenomenon justifies the search for the histopathological tumor regression grading systems ${ }^{[14,20,35,39]}$. Rodel et al ${ }^{[40]}$ suggest that tumor regression following radiotherapy reflects its less aggressive potential resulting from the molecular profile. Particular biological properties of a tumor influencing its chemo-radiosensitivity may also prove to be of long-term prognostic significance, especially in cases submitted to neo-adjuvant therapy.

TRG classification is probably superior versus "T-downstaging" in terms of the evaluation of neoadjuvant therapeutic effects ${ }^{[14]}$. Reports on the relationship between "T-downstaging" or ypT and TRG are not numerous, and are with regard to preoperative longterm radiotherapy and chemoradiotherapy ${ }^{[21,22,35,36]}$. The relationship between TRG and the probability of lymph nodes involvement has been described in detail only in patients with rectal cancer submitted to long-term radiochemotherapy ${ }^{[22,41]}$. So far, no results have been published comparing the NG with other rectal cancer regression assessment systems following neo-adjuvant therapy.

The aim of the present study is to evaluate if two independent histopathological classifications based on semiquantitative assessment of regressive changes may prove useful for the monitoring of patients with rectal adenocarcinoma, initial stage cT3 $\mathrm{NxM} 0$ submitted to preoperative hyperfractionated radiotherapy.

Our particular aim was to assess whether there is any relationship between: (1) "T-downstaging" and histopathological staging systems of cancer response to neo-adjuvant treatment (TRG and NG systems); (2) "T-downstaging" and local tumor stage and lymph node status; (3) TRG and NG classification and local tumor stage and lymph node status; (4) mutual relationships between TRG and NG systems.

\section{MATERIALS AND METHODS}

\section{Patients}

The study encompassed patients with rectal adenocarcinoma submitted to hyperfractionated preoperative radiotherapy, with perirectal tissue invasion assessed with ultrasound examination prior to neo-adjuvant treatment (TRUS: uT3). Patients' general performance status according to the Eastern Cooperative Oncology Group classification ranged from 0 to 2 points. Patients with distant metastases found on chest $\mathrm{X}$-ray, and abdominal and pelvis CT examination were excluded from the study. Also, patients formerly submitted to radiotherapy due to present disease or another neoplasm were not included into the study. None of the patients had a history of inflammatory bowel disease.

Forty patients were included into the study. Median age was 64 (range 45-75) years. Ultrasound examination protocol has been described previously ${ }^{\left[{ }^{[}\right]}$. All patients were submitted to preoperative hyperfractionated radiotherapy. A total dose of $42 \mathrm{~Gy}$ in 28 fractions during $18 \mathrm{~d}$ (twice a day, $1.8 \mathrm{~Gy}, 5 \mathrm{~d} / \mathrm{wk}$, and with a minimum $6 \mathrm{~h}$ interval between doses) using a three-field isocentric techniqueone posterior and two lateral portals. Photon rays of 20 (10-23) MV were used. The edge of the posterior field was situated $5 \mathrm{~cm}$ below the lower tumor margin. The lateral margins of the lateral fields extended beyond the pelvic inlet. The upper edge was at the top of the fifth lumbar vertebra. The target volume included the tumor and regional lymph nodes. The standard size of the posterior 
Table 1 Clinicopathological characteristics of study patients

\begin{tabular}{|c|c|c|}
\hline Median age (mean $\pm \mathrm{SD})(\mathrm{yr})$ & $64(61.75 \pm 10.0)$ & \\
\hline M:F & $1: 1$ & \\
\hline \multicolumn{3}{|c|}{ Lymph node involvement prior to radiotherapy $(\mathrm{cN})$} \\
\hline cN0 & 25 & $62.5 \%$ \\
\hline $\mathrm{cN}+$ & 15 & $37.5 \%$ \\
\hline \multicolumn{3}{|l|}{ Tumor stage } \\
\hline урT0 & 1 & $2.5 \%$ \\
\hline урT1 & 4 & $10 \%$ \\
\hline урT2 & 6 & $15 \%$ \\
\hline урТ3 & 29 & $72.5 \%$ \\
\hline \multicolumn{3}{|l|}{ Lymph node status } \\
\hline ypN0 & 26 & $65 \%$ \\
\hline ypN1 & 8 & $20 \%$ \\
\hline ypN2 & 6 & $15 \%$ \\
\hline $\begin{array}{l}\text { Number of lymph node assessed-median } \\
(\text { mean } \pm \text { SD) }\end{array}$ & $16(18 \pm 11.5)$ & \\
\hline $\begin{array}{l}\text { Number of affected lymph nodes-median } \\
\text { (mean } \pm \text { SD) }\end{array}$ & $0(2.6 \pm 6.9)$ & \\
\hline \multicolumn{3}{|l|}{ Tumor histological grade $(\mathrm{G})^{1}$} \\
\hline G1 & 5 & $12.8 \%$ \\
\hline G2 & 32 & $82.1 \%$ \\
\hline G3 & 2 & $5.1 \%$ \\
\hline Median tumor diameter ${ }^{1}($ mean \pm SD) $(\mathrm{mm})$ & $33.5(33.7 \pm 16.1)$ & \\
\hline
\end{tabular}

${ }^{1}$ One case ypт0 (2.5\%) had not been taken into account.

field was $12 \mathrm{~cm} \times 15 \mathrm{~cm}$ and $10 \mathrm{~cm} \times 15 \mathrm{~cm}$ for the lateral fields. Surgery was performed 1-7 d (mean, $5 \mathrm{~d}$ ) following radiotherapy. Thirty one $(77.5 \%)$ anterior resections, $8(20.0 \%)$ abdomino-perineal resections and $1(2.5 \%)$ Hartmann's operation, were performed.

\section{Pathological examination}

Surgical specimens were submitted to histopathological examination according to standard protocol ${ }^{[42]}$. Special attention was paid to definite, probable and potential prognostic factors ${ }^{[43]}$. The following pathological parameters were evaluated: local tumor stage (ypT), regional lymph node status $(\mathrm{ypN})$, tumor grade $(\mathrm{G} 1, \mathrm{G} 2$, G3), number of metastatic lymph nodes, and parameters of the tumor response to radiotherapy. The latter included: cancer cell degeneration (severe, moderate, mild), mucin pools (absent, present), tumor necrosis (absent, $\leqslant 50 \%$, $>50 \%$ of the tumor), tumor response to radiotherapy according to NG $(1-3)^{\left[{ }^{[3]}\right.}$, and TRG $(1-5)^{[2]]}$ classification. In cases with non-homogeneous tumor response pattern to radiotherapy, the area of the weakest response was taken into account ${ }^{[38]}$. Routine surgical specimens submitted for histopathological examination were evaluated retrospectively. Concerning radiotherapy and surgery, the nature of the study was observatory and not experimental.

\section{Statistical analysis}

A study population was divided into 2 groups upon the "T-downstaging" tumor regression parameter. A group with features of cancer regression, ypT $<\mathrm{uT}(\mathrm{R}$ group) and with no regression, yp $\mathrm{T} \geqslant \mathrm{uT}(\mathrm{NR}$ group) were distinguished. The differences between groups in parameters studied were tested using Pearson's $\chi^{2}$ test,
Table 2 Relationship between "T-downstaging" and prognostic parameters

\begin{tabular}{|c|c|c|c|}
\hline Feature & Group $R(n=11)$ & Group NR $(n=29)$ & $P$ \\
\hline $\begin{array}{l}\text { Median age (range) } \\
(\text { mean } \pm \text { SD) (yr) }\end{array}$ & $70(55-77)(67.7 \pm 7.2)$ & $61(45-70)(59.4 \pm 9.9)$ & $<0.05$ \\
\hline Tumor stage & & & $<0.000$ \\
\hline урТ0 & $1(9.1 \%)$ & 0 & \\
\hline урT1 & $4(36.4 \%)$ & 0 & \\
\hline урТ2 & $6(54.6 \%)$ & 0 & \\
\hline урТ3 & 0 & $29(100.0 \%)$ & \\
\hline TRG & & & $<0.08$ \\
\hline 1 & $1(9.1 \%)$ & 0 & \\
\hline 2 & $2(18.2 \%)$ & $1(3.5 \%)$ & \\
\hline 3 & $6(54.6 \%)$ & $11(37.9 \%)$ & \\
\hline 4 & $2(18.2 \%)$ & $14(48.3 \%)$ & \\
\hline 5 & 0 & $3(10.3 \%)$ & \\
\hline NG & & & $<0.08$ \\
\hline 1 & $5(45.5 \%)$ & $4(13.8 \%)$ & \\
\hline 2 & $2(18.2 \%)$ & $4(13.8 \%)$ & \\
\hline 3 & $4(36.4 \%)$ & $21(72.4 \%)$ & \\
\hline
\end{tabular}

Fisher's exact test, and Mann-Whitney's $U$ test. Correlation was assessed with Spearman's rank correlation. $P<0.05$ was considered statistically significant.

\section{RESULTS}

Demographic data and staging parameters are presented in Table 1. Local tumor stage, ypT3 was found in 29 (72.5\%) patients. "T-downstaging" was observed in 11 out of $40(27.5 \%)$ patients. Six $(15.0 \%)$ of them showed downstaging to ypT2, and $4(10.0 \%)$ to ypT1. In one case, histopathological examination has shown no evidence of carcinoma in the intestinal wall (ypT0, TRG 1). Also, no lymph node involvement was found in this patient (ypT0N0). TRUS examination showed features of lymph node involvement in $15(37.5 \%)$ patients. In $8(20 \%)$ of 15 patients in whom TRUS examination showed lymph node involvement, microscopic examination revealed stage ypN0. In $7(17.5 \%)$ out of 25 patients with no evidence of lymph node involvement in TRUS examination, histopathological examination showed presence of metastases. TRG grades 2, 3 and 4 were diagnosed in 3 $(7.5 \%), 17(42.5 \%)$ and $16(40.0 \%)$ patients, respectively. No tumor regression (TRG 5) was found in $3(7.5 \%)$ patients. Features of moderate or severe cancer cell degeneration were observed in $17(42.5 \%)$ patients. Mucus lakes were seen in $22(55.0 \%)$ cases. Necrosis was present in $27(67.5 \%)$ of cases including 1 case with more than $50 \%$ of tumor involvement. Stage 1,2 , and 3 of NG classification was reported in $9(22.5 \%), 6(15.0 \%)$, and 25 $(62.5 \%)$ patients, respectively.

Median age (range) in the group with tumor regression was higher than those of patients with no evidence of regression (Table 2). Groups R and NR included 5 (45.5\%) and $15(51.7 \%)$ men (NS), respectively. TRUS examination performed prior to neo-adjuvant therapy revealed lymph node involvement in groups $\mathrm{R}$ and NR in $4(36.36 \%)$ and $11(37.93 \%)$ patients (NS), respectively. Stage ypNo, ypN1 and ypN2 was found in $9(81.8 \%), 2(18.2 \%)$, and 
Table 3 Relationship between tumor stage and TRG

\begin{tabular}{lccccc}
\hline & TRG 1 & TRG 2 & TRG 3 & TRG 4 & TRG 5 \\
\hline Local tumor stage $^{1, a}$ & & & & & \\
ypT0 & 1 & - & - & - & - \\
ypT1 & - & 2 & 2 & - & - \\
ypT2 & - & - & 4 & 2 & - \\
ypT3 & - & 1 & 11 & 14 & 3 \\
Lymph nodes involvement & 2, & & & & \\
ypN0 & 1 & 3 & 14 & 8 & - \\
ypN1 & - & - & 1 & 5 & 2 \\
ypN2 & - & - & 2 & 3 & 1 \\
\hline
\end{tabular}

${ }^{1}$ Spearman R correlation $r=0.47$; ${ }^{\mathrm{a}} P<0.005$, comparison between different local tumor stages. ${ }^{2}$ Spearman R correlation $r=0.47 ;{ }^{\mathrm{c}} P<0.005$, comparison between different lymph nodes involvements.

0 patients in group $\mathrm{R}$ and 17 (58.6\%), $6(20.7 \%)$ and 6 $(20.7 \%)$ in group NR (NS). A trend $(P<0.12)$ indicating a relationship between the number of lymph nodes assessed and "T-downstaging" was found. Median (range) number of lymph nodes in group R was 11 (3-35), and 17 (3-41) in group NR. The number of involved lymph nodes in the group $\mathrm{R}$ (median, range) did not differ from the number of nodes in group NR, $0(0-1)$ and $0(0-35)$ (NS), respectively. Tumor grade G1 was found in $2(20.0 \%)$ patients, G2 in 7 (70.0\%), and G3 in $1(10.0 \%)$ patient in the $\mathrm{R}$ group, and in $3(10.3 \%), 25(86.2 \%)$, and $1(3.5 \%)$ patients in the NR group (NS); one (2.5\%) case at the ypT0 stage had not been taken into account. Median (range) tumor diameter in groups $\mathrm{R}$ and $\mathrm{NR}$ was 26 (10-65) $\mathrm{mm}$ and 35 (10-70) $\mathrm{mm}$, respectively (NS). The relationship between "T-downstaging" and TRG staging as well as the NG stage was at the borderline of statistical significance. The relationship between TRG and NG vs. local tumor stage and lymph node status is shown in Tables 3 and 4. Patients with ypT1 were diagnosed as TRG 2-3. Patients with TRG5 were classified as ypT3. No lymph node metastases were found in patients with TRG 1-2 (ypN0). None of the patients without lymph nodes metastases were diagnosed as TRG 5. Patients in the ypT1 stage were diagnosed as NG 1-2. No lymph node metastases were found in NG 1. There was a relationship between TRG and NG (correlation $R=0.58, P<0.01$ ). Patients with TRG $1-2$ were classified as NG 1. Patients with TRG 5 were diagnosed as NG 3.

\section{DISCUSSION}

Ultrasound-histopathological tumor regression parameter, "T-downstaging" represents a simple marker of rectal cancer radiosensitivity both in patients submitted to shortterm preoperative radiotherapy ${ }^{[11,18,19,44,45]}$ as well as in patients with surgery delayed by 1 to 8 wk following irra diation ${ }^{[17,20,21,23,25-28,34-36,39,46-49]}$. Reports have been published showing the prognostic value of "T-downstaging" for overall survival ${ }^{[17,28,34]}$, cancer-specific survival ${ }^{[48]}$, recurrence-free survival ${ }^{[48]}$, disease-free survival ${ }^{[25,28]}$, local recurrence risk ${ }^{[2,34,48]}$, and the risk of distant metastases ${ }^{[48]}$. Read $e t a l^{[50]}$ showed that the local staging following neo-adjuvant therapy enables the risk assessment of
Table 4 Relationship between tumor stage and NG

\begin{tabular}{lccc}
\hline & NG 1 & NG 2 & NG 3 \\
\hline Local tumor stage $^{1, \mathrm{~b}}$ & & & \\
ypT0 & 1 & - & - \\
ypT1 & 3 & 1 & - \\
ypT2 & 1 & 1 & 4 \\
ypT3 & 4 & 4 & 21 \\
Lymph node involvement ${ }^{2, a}$ & & & \\
ypN0 & 9 & 5 & 12 \\
ypN1 & - & - & 8 \\
ypN2 & - & 1 & 5 \\
\hline
\end{tabular}

${ }^{\mathrm{l}}$ Spearman R correlation $r=0.42{ }^{\mathrm{b}} \mathrm{P}<0.01$, comparison between different local tumor stages. ${ }^{2}$ Spearman R correlation $r=0.45 ;{ }^{\mathrm{a}} P<0.005$, comparison of lymph node involvement.

lymph node metastases. This finding may prove to be of significance during planning of surgical treatment. The percentage of patients with "T-downstaging" in the group submitted to long-term radiotherapy and radiochemotherapy ranged from $23 / 88(26.0 \%)$ to $15 / 20$ $(75.0 \%)^{[14,17,20-24,27,34-36,39,46-49,51,52]}$. Among patients submitted to short-term preoperative radiotherapy "T-downstaging" ranged between $10 / 28(35.7 \%)$ and $44 / 104(43 \%)^{[1,14,18,19]}$. An alternative way for the assessment of local tumor stage decrease is comparison of $\mathrm{yp} T$ in patients from study groups and control groups in randomized trials on the effects of neo-adjuvant therapy ${ }^{[53]}$. Results of randomized studies on effects of short-term preoperative radiotherapy with a dose of $25 \mathrm{~Gy}$ on local tumor stage were discrepant ${ }^{[8,44]}$. In the presented material, "T-downstaging" was achieved in 11/40 (27.5\%) patients. No correlation between "T-downstaging" and lymph node involvement, tumor grade and its diameter were found. In patients submitted to neo-adjuvant therapy the number of assessed lymph nodes is usually lower than in patients treated with surgery only ${ }^{[54]}$. In the present study, a tendency towards statistical significance $(P<0.12)$ of the correlation between "T-downstaging" and the number of evaluated lymph nodes was observed. More lymph nodes were found in patients with local stage ypT3 (group NR) than in those with ypT0-2 stage. Joseph et al ${ }^{[55]}$ showed that in patients with colon cancer at $\mathrm{T} 1 / \mathrm{T} 2$ stage more lymph nodes must be studied than in patients with T3/T4 in order to reliably define stage pNO. However, frequently the surgical approach is completely different in patients with lower local stage a limited lymph node resection is performed ${ }^{[57]}$.

In the presented study, "downstaging" parameter was evaluated exclusively in order to show cancer regression within the rectal wall ("T-downstaging"). This results from the fact that the sensitivity of ultrasound evaluation of affected lymph nodes prior to radiotherapy is probably not sufficient to make a reference point for other, strictly histopathological tumor regression classifications. The accuracy of ultrasound examination in the evaluation of lymph node involvement is $65 \%-81 \%$ and the accuracy of the local tumor stage assessment is $82 \%$ to $93 \%{ }^{[3]}$. Another argument against uN parameter in the evaluation of rectal cancer regression is that $\mathrm{uN}$ is of 
no prognostic significance ${ }^{[17,49]}$. Some authors studied "N-downstaging" parameter ${ }^{[17,20,22-26,36,47]}$ and showed its prognostic value ${ }^{[17]}$. The percentage of patients submitted to radiochemotherapy or radiotherapy with long time intervals between neo-adjuvant treatment and surgery, in which "N-downstaging" was noted, ranged from 13/26 $(50.0 \%)$ to $38 / 42(90.4 \%)^{[17,20,22-26,36,47]}$. Tumor size decrease, 'sterilization' and lymph node atrophy are the classic effects of radiotherapy ${ }^{[20,44,45]}$. Graf et al ${ }^{[53]}$ showed that short-term preoperative radiotherapy results in decreased risk of lymph node involvement.

TRG 1 indicates that no cancer cells have been identified in the rectal wall ${ }^{[18,19,21,29]}$. Some researchers refer TRG 1 to patients with no cancer cells in the entire post-surgical specimen ${ }^{[37]}$. The termpathological complete response ( $\mathrm{pCR}$ ) of rectal cancer to preoperative radiotherapy regards the situation in which histopathological examination does not show the neoplasm in the rectal wall, lymph nodes and mesorectum ${ }^{[25,26,35-38,46,48-50,57-61]}$. This is in accordance with the definition developed by the WHO initiative ${ }^{[62]}$. A stage of pCR is sometimes identified with ypT0N0 the situation in which there is no evidence of neoplastic tissue in the rectal wall and in the lymph nodes ${ }^{[17,23]}$. Cases with only a few residual cells or small clusters of cells detected in histopathological examination of surgical specimens are by some authors classified as $\mathrm{pCR}^{[63]}$. In the presented study, the authors have assumed that the term pCR represents the situation in which no cancer cells were found in the surgical specimen. There is no absolute concordance between pCR and clinical complete response (assessed by per rectum digital examination and in proctoscopy): pCR may regard barely $25.0 \%$ of patients submitted to long-term preoperative chemoradiotherapy with clinical complete response ${ }^{[61]}$. A complete response to radiotherapy in comparison with the presence of residual cancer tissue is associated with better overall survival rate $^{[46]}$, longer disease-free survival ${ }^{[25]}$, and lower risk of local recurrence ${ }^{[46]}$. However, some authors claim that complete regression is of no prognostic significance ${ }^{[37]}$. Guillem et at ${ }^{[59]}$ did not show any differences in long-term prognosis among patients with complete cancer regression in comparison with almost complete response $(\geqslant 95.0 \%$ regression) to neo-adjuvant therapy.

Demonstrating a complete remission is important not only because of its prognostic value but also because of the need of assessment of indications for the postoperative chemotherapy or radiotherapy, for the decision about the appropriate method of surgery ${ }^{[20,37,45,46,}$ $49,57,58,63,64]$ or to compare the effects of different treatment methods ${ }^{[45]}$. Zmora et al ${ }^{[58]}$ showed that metastases to regional lymph nodes and cancer cells in the mesorectal tissue may be present in patients with complete tumor regression within the rectal wall (TRG 1 , ypT0) ${ }^{[58]}$. However, neo-adjuvant therapy makes it possible to reduce the percentage of patients submitted to abdominoperineal resection and, in some cases, to perform local tumor excision ${ }^{[15,25,41,49,64-67]}$. Randomized study conducted by Polish researchers on a group of 316 patients treated with long-term radiochemotherapy or short-term preoperative radiotherapy did not show differences in terms of sphincter preservation rate $(58 \%$ vs $61 \%, P=$ $0.57)^{[67]}$. Appropriate selection of the study patients treated with local excision is a very important issue ${ }^{[41,64-66,68]}$. The local tumor stage seems to be a reliable predictor of lymph node regression in these patients ${ }^{[41,64]}$. The assessment of eventual residual cancer, local stage (ypT), surgical clearance in the resection margins in patients submitted to local resection may reveal the necessity of immediate radical resection (performed within $30 \mathrm{~d}$ after the primary surgery $)^{[65,66,68]}$. Also, intraoperative frozen section may prove useful for the assessment of tumor stage and margins' status. In cases in which a more advanced stage (p'2 or p'3) is likely to be found at the time of surgery or where the surgical clearance could be doubtful, the patient should be prepared for the possibility of wide excision at the same operation ${ }^{[6]}$.

Another interesting issue is the assessment of cancer regression following neo-adjuvant therapy with use of TRG classification on intraoperational microscopic examination. In particular, this regards patients with an evident but incomplete regression. One could expect that the lacking concordance between local tumor stage ypT and TRG in post-operative histopathological examination, as mentioned above, apply also to intraoperation evaluation ${ }^{[20,35,39]}$. Considering the fact, that local excision following neo-adjuvant treatment is a therapeutic option for carefully selected patients, it could be eventually considered in patients with an evident but incomplete tumor regression. These patients are characterized by a low risk of local recurrence ${ }^{[18,22]}$. In the present study we have observed 1 case of coincidence of ypT3 and TRG 2. In the absence of reliable alternative methods, microscopic examination plays an important role in the evaluation of cancer regression following neo-adjuvant treatment. Digital rectal examination, computerized tomography, transrectal ultrasound examination and magnetic resonance are of limited value in terms of assessment of residual cancer following long-term pre-operative radio- and radiochemotherapy, especially to demonstrate $\mathrm{pCR}^{[61,69]}$. However, Gavioli et a ${ }^{[70]}$ believe that TRUS is a very useful tool, when the same experienced operator performs it before and after neo-adjuvant treatment since it leads to demonstrate tumor regression in a qualitative and quantitative way. Moreover, they proposed that TRUS performed 6-8 wk following irradiation makes it possible to visualize fibrous changes only, which does not, however, disqualify this diagnostic method. The extent of fibrosis indicates the possible depth of residual cancer infiltrationcancer cells are believed to be present within fibrous areas only ${ }^{[70]}$. The use of magnetic resonance volumetry may also be useful in quantitative assessment of cancer regression following neo-adjuvant treatment ${ }^{[71]}$. The difficulties in achieving high level of reliability of visualizing diagnostic methods result from similar signal intensity (echogenity) between residual cancer, fibrous tissue, mucus pools and peritumoral inflammatory infiltration ${ }^{[71]}$. The use of 18-fluorodeoxyglucose positron emission tomography may prove effective in assessment of tumor response to neo-adjuvant therapy ${ }^{[33]}$. Full thickness local excision still 
remains an experimental treatment method ${ }^{[64]}$.

The significance of $\mathrm{pCR}$ following radiotherapy has not been ultimately confirmed. It is possible that better longterm survival in patients with pCR results from different biological properties of the tumor. Also, interesting reports have been presented, showing that patients submitted to neo-adjuvant chemotherapy and receiving statins showed higher a pCR rate ${ }^{[72]}$. The percentage of patients with complete regression following longterm radiochemotherapy and radiotherapy ranged from $1 / 43(2.3 \%)$ to $7 / 20(35.0 \%)^{[5,17,20-21,23-27,35-37,47-52,57-61,67,73]}$. The percentage of patients presenting complete cancer regression following short-term radiotherapy ranges between $0 \%$ and $10 / 191(5.2 \%)^{[10,11,18,19,50]}$. In the present study we have observed 1 case $(2.5 \%)$ with complete tumor regression.

The period between the termination of neo-adjuvant therapy and surgery in long-term radiochemotherapy and radiotherapy schemes is a few days and a few weeks, respectively. One may assume that short-term radiotherapy will result in relatively lesser tumor regression ${ }^{[10,23,63]}$. The results obtained in large study groups indicate that the short-term radiotherapy results not only in a decrease of the tumor diameter ${ }^{[44,45,53]}$, but also in decreased number of affected lymph nodes ${ }^{[53]}$. A decrease in tumor diameter is not, however, equivalent with the decrease in local extent of tumor. Some authors believe that the period shorter than $10 \mathrm{~d}$ is insufficient to achieve tumor regression following radiotherapy with a dose of $25 \mathrm{~Gy}^{[45]}$. The proposition of the role of the time period between neoadjuvant treatment and the percentage of pCR has its supporters ${ }^{[26,63]}$ and opponents ${ }^{[24,73]}$. It was, however, shown that the period of a few days between the termination of neo-adjuvant therapy and surgery is sufficient enough for the development of morphological changes within the tumor and in its gene expression profile ${ }^{[44,74]}$.

It was demonstrated that there is a relationship between TRG and overall survival, disease-free survival, and the risk of local tumor recurrence ${ }^{[18,22]}$. Other authors suggest that TRG estimation does not enable long-term prognosis in patients with rectal cancer ${ }^{[37]}$. There are some doubts regarding the reliability of this classification due to its subjective nature ${ }^{[20]}$. Interobserver variability of the TRG system was found to be satisfactory (kappa 0.64) or mediocre (kappa 0.44). It is higher when a 5-point system is simplified to 3 -point ${ }^{[21,38]}$. For the reliability assessment it is important that significant fibrosis may accompany neoplastic tissue even when no neo-adjuvant therapy had been administered ${ }^{[38]}$. In the presented study, we have not shown unequivocal correlation between "T-downstaging" and TRG. We have found a correlation of TRG and yp T parameters. The reliability of TRG as a lymph node predictor is not unequivocal. Veccio et al ${ }^{[22]}$ showed that lymph node involvement is not observed in $41 / 45$ $(91.0 \%)$ patients submitted to long-term preoperative chemoradiotherapy at TRG 1-2 stage. Kim et al ${ }^{[41]}$ showed that histopathological assessment of tumor response to preoperative long-term radiochemotherapy (performed with use of the method described by Dworak et a ${ }^{[32]}$, similar to the TRG system) is, along with ypT, an independent predictor of lymph node involvement. In the present study, ypN0 stage was observed in all patients with TRG 1-2. We have not found any definite relationship between "T-downstaging" and the NG stage. The results indicate the correlation between TRG and NG. However, these classifications are based on the evaluation of different morphological parameters. Rectal Cancer Regression Grade (RCRG) classification proposed by Wheeler et al ${ }^{[20,39]}$ is next to the TRG system and Dworak et al ${ }^{[32]}$ classification, one of the most widely used in studies documenting rectal cancer regression following neoadjuvant therapy. It defines 3 degrees of tumor regression: 1 , no cancer nests or microscopic collections of cancer cells embedded in fibrous stroma; 2, residual neoplasm seen grossly but with evident fibrosis; 3, carcinoma seen grossly with discreet or absent fibrosis. According to some researchers, such distinguishing of neoplastic tissue and fibrosis is not reliable ${ }^{[38,58]}$. Due to these reservations and the retrospective nature of the study, this grading system had not been taken into consideration in the present study.

At present, there is no uniform, widely accepted histopathological classification used for the evaluation of rectal cancer regression following preoperative radiotherapy. As far as the need for evaluation of residual cancer raises no objections, its interpretation and clinical consequences of radiation-induced changes in the rectal wall and within the tumor are not clear ${ }^{[5,27,44,74]}$. It is also unclear to what extent the presence of necrosis one may assign to its radiotherapeutic effect and to what extent it is a result of ischemic changes due to local perfusion disturbance. Fibrosis that accompanies neoplastic tumor may reflect both natural protective body mechanisms as well as being a result of chronic inflammation ${ }^{[7]}$. Mucin pools in tissues previously occupied by neoplastic tissue are qualitatively different from changes described as colitis cystica profunda, which may develop within the normal intestinal wall following radiotherapy ${ }^{[20]}$. The presence of mucin pools (induced mucinous carcinoma, colloid response) should be taken into account in the differential diagnosis of mucus-secreting adenocarcinoma ${ }^{[28,74]}$. The prognostic value of other morphological changes observed within the residual neoplastic tissue (the intensity and the nature of inflammatory infiltrations accompanying fibrous tissue and cancer cell clusters, cancer cell nuclear pleomorphism and hyperchromasia, mucinous cancer component, low tumor histological grade) and in the intestinal wall (surface ulceration, dysplastic changes, lowgrade adenoma component) has not been unequivocally established $^{[27,44,74]}$. Figures 1, 2, 3, 4, 5 and 6 show examples of neo-adjuvant therapy induced changes.

The retrospective nature of the presented study and the relatively small group of study patients impose careful interpretation of the presented results. Few reports on "T-downgrading", TRG and NG in patients submitted to short-term radiotherapy according to the regimen presented make the presented results suitable for further prospective studies on a larger population.

In conclusion, histopathological classifications based on the assessment of regressive changes may be useful in the 


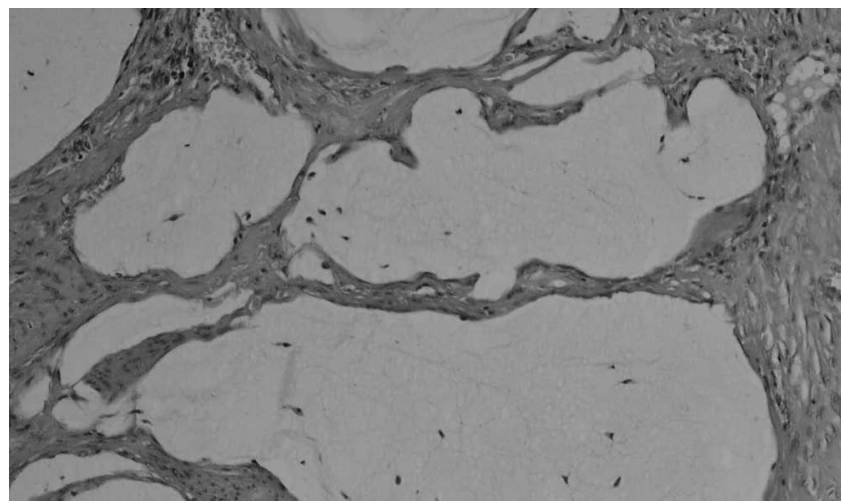

Figure 1 Acellular mucin pools in the intestinal wall (HE x 200).

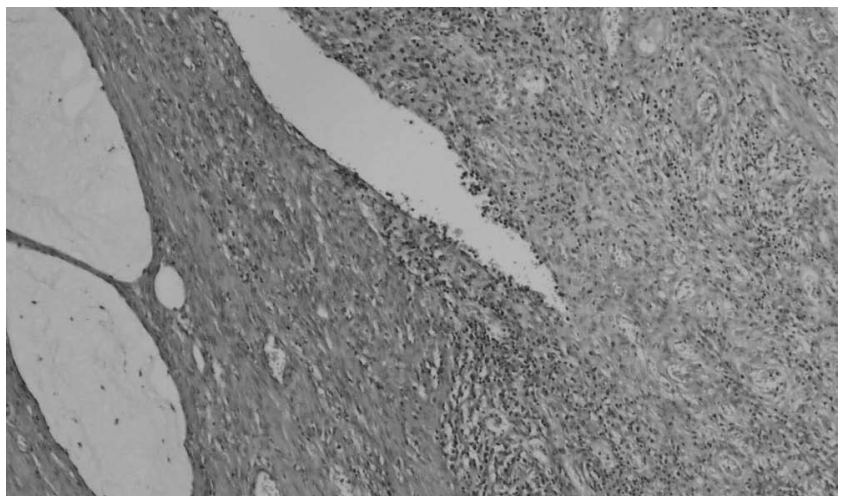

Figure 2 Complete tumor regression following radiotherapy. Inflammatory infiltrations, mucin pool and focal fibrosis in the stroma (HE x 64).

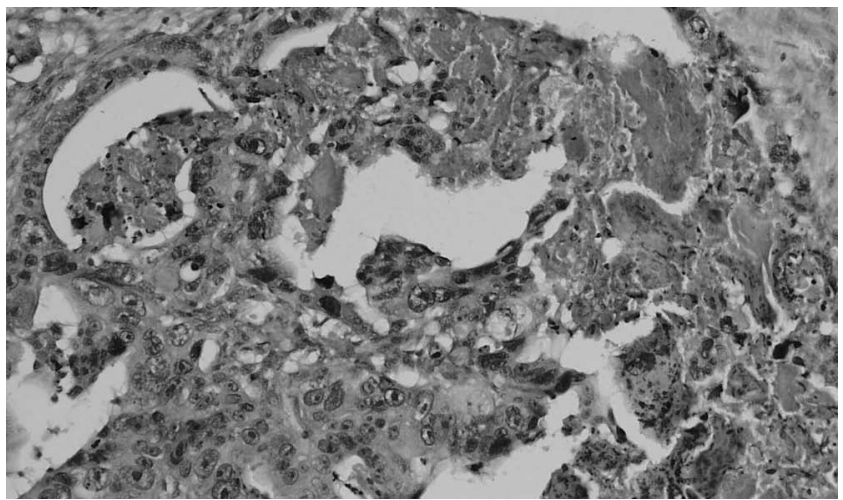

Figure 3 Degeneration and necrosis of tumor cells following radiotherapy (HE x 250).

monitoring of effects of hyperfractionated preoperative radiotherapy in patients with rectal cancer at the initial stage of cT3NxM0. There is no unequivocal relationship between "T-dowstaging" and the tumor regression assessed with TRG and Nasierowska-Guttmejer classification. Poor tumor regression was seen more frequently in patients with no evident "T-downstaging". No relationships have been found between "T-downstaging" and lymph node involvement, tumor histological grade or tumor diameter. There is a clear but limited concordance in the assessment of regressive changes with ypT and TRG or NG. TRG

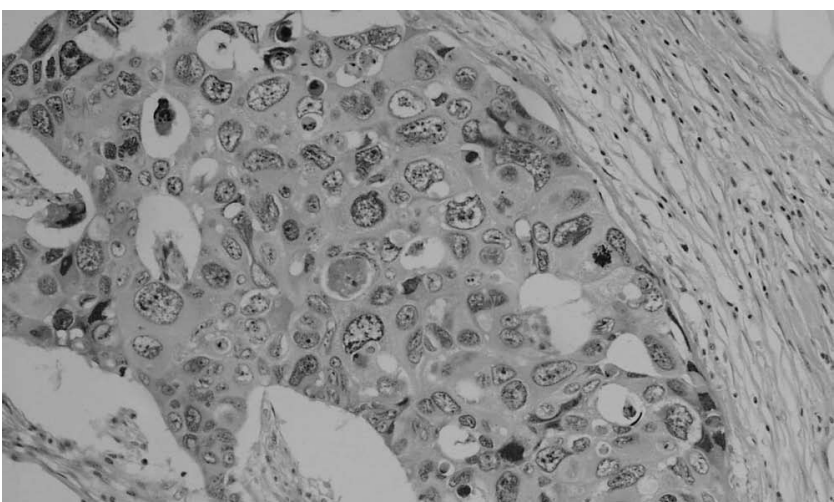

Figure 4 Degenerated adenocarcinoma cells following radiotherapy (HE x 125).

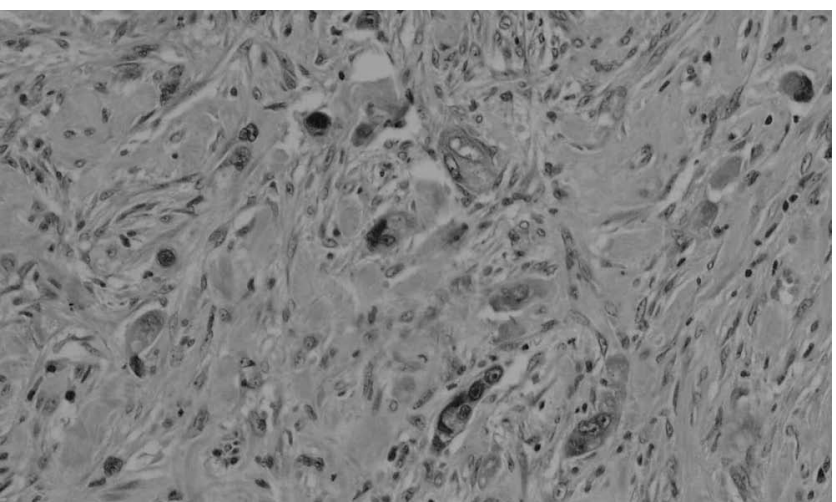

Figure 5 Dispersed degenerated adenocarcinoma cells following radiotherapy (HE x 125).

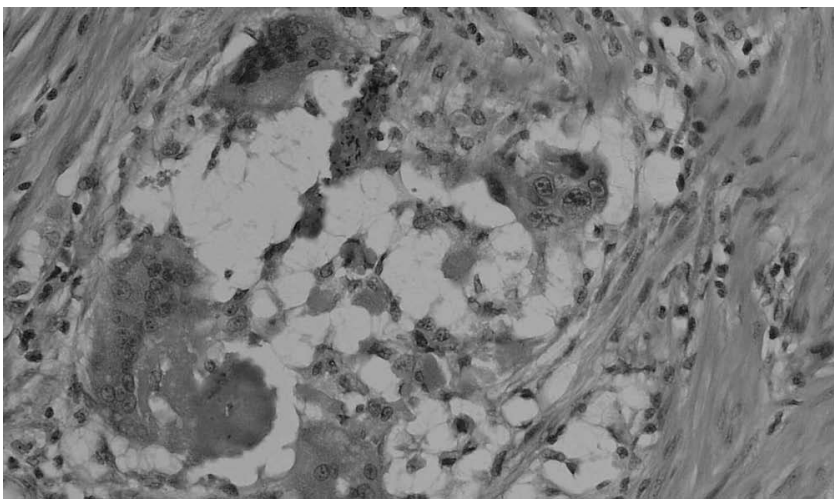

Figure 6 Macrophages and multinucleated (giant) cells close to necrotic tumor areas (HE x 200).

and NG classifications are probably of limited predictive value in terms of lymph node involvement. There is a non-coincidental relationship between the assessment of radiation-induced regressive changes with use of TRG and NG classifications.

It is possible that immunohistochemical evaluation or molecular biology techniques applied to pre-operative biopsy samples may prove to be of predictive value in the future ${ }^{[21,34,52,75]}$. Undoubtedly, histopathological evaluation of the neoplastic tissue regression following preoperative radiotherapy is very important and necessary, 
since ultrasound examination here is of limited reliability. Histopathological evaluation of rectal cancer regression may also prove to be useful for the evaluation of the effectiveness of future radio- and radio-chemotherapeutic treatment methods. It might also enable to isolate the population of rectal cancer patients in whom the adjuvant treatment would be especially justified.

\section{REFERENCES}

1 National Comprehensive Cancer Network. Rectal Cancer. Clinical Practice Guidelines in Oncology. Version 2.2006; cited 2006-04-24. Available from: URL: http://www.nccn.org/ professionals/physician_gls/PDF/rectal.pdf

2 Jemal A, Siegel R, Ward E, Murray T, Xu J, Smigal C, Thun MJ. Cancer statistics, 2006. CA Cancer J Clin 2006; 56: 106-130

3 Church JM, Gibbs P, Chao MW, Tjandra JJ. Optimizing the outcome for patients with rectal cancer. Dis Colon Rectum 2003; 46: $389-402$

4 Tjandra JJ, Kilkenny JW, Buie WD, Hyman N, Simmang C, Anthony T, Orsay C, Church J, Otchy D, Cohen J, Place R, Denstman F, Rakinic J, Moore R, Whiteford M. Practice parameters for the management of rectal cancer (revised). Dis Colon Rectum 2005; 48: 411-423

5 Nasierowska-Guttmejer A. Histopathological and immunohistochemical markers in rectal cancer after preoperative radiochemotherapy. J Oncol 2001; 51 Suppl 3: 1-57 (in Polish, with English abstract)

6 Pawelczyk I, Pajak J, Wydmanski J, Kozera J, Dyczkowski $\mathrm{K}$, Lorek A. The usefulness of transrectal ultrasound for assessment of local progression of rectal cancer after hyperfractionated preoperative radiotherapy. Chir Pol 2001; 4: 163-170. Available from: URL:http://www.chirurgia.med. pl/en/darmowy_pdf.phtml?indeks=4\&indeks_art=

7 Wheeler JM, Warren BF, Jones AC, Mortensen NJ. Preoperative radiotherapy for rectal cancer: implications for surgeons, pathologists and radiologists. Br J Surg 1999; 86: 1108-1120

8 Improved survival with preoperative radiotherapy in resectable rectal cancer. Swedish Rectal Cancer Trial. N Engl J Med 1997; 336: 980-987

9 Folkesson J, Birgisson H, Pahlman L, Cedermark B, Glimelius B, Gunnarsson U. Swedish Rectal Cancer Trial: long lasting benefits from radiotherapy on survival and local recurrence rate. J Clin Oncol 2005; 23: 5644-5650

10 Nasierowska-Guttmejer A. The comparison of immunohistochemical proliferation and apoptosis markers in rectal carcinoma treated surgically or by preoperative radiochemotherapy. Pol J Pathol 2001; 52: 53-61

11 Voelter V, Stupp R, Matter M, Gillet M, Bouzourene H, Leyvraz S, Coucke P. Preoperative hyperfractionated accelerated radiotherapy (HART) and concomitant CPT-11 in locally advanced rectal carcinoma: a phase I study. Int J Radiat Oncol Biol Phys 2003; 56: 1288-1294

12 Coucke PA, Sartorelli B, Cuttat JF, Jeanneret W, Gillet M, Mirimanoff RO. The rationale to switch from postoperative hyperfractionated accelerated radiotherapy to preoperative hyperfractionated accelerated radiotherapy in rectal cancer. Int J Radiat Oncol Biol Phys 1995; 32: 181-188

13 Cammà C, Giunta M, Fiorica F, Pagliaro L, Craxì A, Cottone M. Preoperative radiotherapy for resectable rectal cancer: A meta-analysis. JAMA 2000; 284: 1008-1015

14 Vironen J, Juhola M, Kairaluoma M, Jantunen I, Kellokumpu I. Tumour regression grading in the evaluation of tumour response after different preoperative radiotherapy treatments for rectal carcinoma. Int J Colorectal Dis 2005; 20: 440-445

15 Rengan R, Paty P, Wong WD, Guillem J, Weiser M, Temple L, Saltz L, Minsky BD. Distal cT2N0 rectal cancer: is there an alternative to abdominoperineal resection? J Clin Oncol 2005; 23: 4905-4912

16 Heimann TM, Szporn AH. Color atlas of preoperative staging and surgical treatment options in rectal cancer. 1st ed.
Baltimore: Williams and Wilkins, 1998: 40-49

17 Roman S, Cenni JC, Roy P, Pujol B, Napoleon B, KerivenSouquet $\mathrm{O}$, Souquet JC. Value of rectal ultrasound in predicting staging and outcome in patients with rectal adenocarcinoma. Dis Colon Rectum 2004; 47: 1323-1330

18 Bouzourene H, Bosman FT, Matter M, Coucke P. Predictive factors in locally advanced rectal cancer treated with preoperative hyperfractionated and accelerated radiotherapy. Hum Pathol 2003; 34: 541-548

19 Bouzourene H, Bosman FT, Seelentag W, Matter M, Coucke P. Importance of tumor regression assessment in predicting the outcome in patients with locally advanced rectal carcinoma who are treated with preoperative radiotherapy. Cancer 2002; 94: 1121-1130

20 Wheeler JM, Warren BF, Mortensen NJ, Ekanyaka N, Kulacoglu H, Jones AC, George BD, Kettlewell MG. Quantification of histologic regression of rectal cancer after irradiation: a proposal for a modified staging system. Dis Colon Rectum 2002; 45: 1051-1056

21 Morgan MJ, Koorey DJ, Painter D, Findlay M, Tran K, Stevens G, Solomon MJ. Histological tumour response to pre-operative combined modality therapy in locally advanced rectal cancer. Colorectal Dis 2002; 4: 177-183

22 Vecchio FM, Valentini V, Minsky BD, Padula GD, Venkatraman ES, Balducci M, Miccichè F, Ricci R, Morganti AG, Gambacorta MA, Maurizi F, Coco C. The relationship of pathologic tumor regression grade (TRG) and outcomes after preoperative therapy in rectal cancer. Int J Radiat Oncol Biol Phys 2005; 62: 752-760

23 Moore HG, Gittleman AE, Minsky BD, Wong D, Paty PB, Weiser M, Temple L, Saltz L, Shia J, Guillem JG. Rate of pathologic complete response with increased interval between preoperative combined modality therapy and rectal cancer resection. Dis Colon Rectum 2004; 47: 279-286

24 Stein DE, Mahmoud NN, Anné PR, Rose DG, Isenberg GA, Goldstein SD, Mitchell E, Fry RD. Longer time interval between completion of neoadjuvant chemoradiation and surgical resection does not improve downstaging of rectal carcinoma. Dis Colon Rectum 2003; 46: 448-453

25 Theodoropoulos G, Wise WE, Padmanabhan A, Kerner BA, Taylor CW, Aguilar PS, Khanduja KS. T-level downstaging and complete pathologic response after preoperative chemoradiation for advanced rectal cancer result in decreased recurrence and improved disease-free survival. Dis Colon Rectum 2002; 45: 895-903

26 Ratto C, Valentini V, Morganti AG, Barbaro B, Coco C, Sofo L, Balducci M, Gentile PC, Pacelli F, Doglietto GB, Picciocchi A, Cellini N. Combined-modality therapy in locally advanced primary rectal cancer. Dis Colon Rectum 2003; 46: 59-67

27 Shia J, Guillem JG, Moore HG, Tickoo SK, Qin J, Ruo L, Suriawinata A, Paty PB, Minsky BD, Weiser MR, Temple LK, Wong WD, Klimstra DS. Patterns of morphologic alteration in residual rectal carcinoma following preoperative chemoradiation and their association with long-term outcome. Am J Surg Pathol 2004; 28: 215-223

28 Rullier A, Laurent C, Vendrely V, Le Bail B, BioulacSage P, Rullier E. Impact of colloid response on survival after preoperative radiotherapy in locally advanced rectal carcinoma. Am J Surg Pathol 2005; 29: 602-606

29 Mandard AM, Dalibard F, Mandard JC, Marnay J, HenryAmar M, Petiot JF, Roussel A, Jacob JH, Segol P, Samama G. Pathologic assessment of tumor regression after preoperative chemoradiotherapy of esophageal carcinoma. Clinicopathologic correlations. Cancer 1994; 73: 2680-2686

30 Spitz FR, Giacco GG, Hess K, Larry L, Rich TA, Janjan N, Cleary KR, Skibber JM. p53 immunohistochemical staining predicts residual disease after chemoradiation in patients with high-risk rectal cancer. Clin Cancer Res 1997; 3: 1685-1690

31 Berger C, de Muret A, Garaud P, Chapet S, Bourlier P, Reynaud-Bougnoux A, Dorval E, de Calan L, Huten N, le Folch $\mathrm{O}$, Calais G. Preoperative radiotherapy (RT) for rectal cancer: predictive factors of tumor downstaging and residual tumor cell density (RTCD): prognostic implications. Int J Radiat Oncol 


\section{Biol Phys 1997; 37: 619-627}

32 Dworak O, Keilholz L, Hoffmann A. Pathological features of rectal cancer after preoperative radiochemotherapy. Int J Colorectal Dis 1997; 12: 19-23

33 Guillem JG, Puig-La Calle J, Akhurst T, Tickoo S, Ruo L, Minsky BD, Gollub MJ, Klimstra DS, Mazumdar M, Paty PB, Macapinlac H, Yeung H, Saltz L, Finn RD, Erdi Y, Humm J, Cohen AM, Larson S. Prospective assessment of primary rectal cancer response to preoperative radiation and chemotherapy using 18-fluorodeoxyglucose positron emission tomography. Dis Colon Rectum 2000; 43: 18-24

34 Saw RP, Morgan M, Koorey D, Painter D, Findlay M, Stevens G, Clarke S, Chapuis P, Solomon MJ. p53, deleted in colorectal cancer gene, and thymidylate synthase as predictors of histopathologic response and survival in low, locally advanced rectal cancer treated with preoperative adjuvant therapy. Dis Colon Rectum 2003; 46: 192-202

35 Gambacorta MA, Valentini V, Morganti AG, Mantini G, Miccichè F, Ratto C, Di Miceli D, Rotondi F, Alfieri S, Doglietto GB, Vargas JG, De Paoli A, Rossi C, Cellini N. Chemoradiation with raltitrexed (Tomudex) in preoperative treatment of stage II-III resectable rectal cancer: a phase II study. Int J Radiat Oncol Biol Phys 2004; 60: 130-138

36 Valentini V, Coco C, Cellini N, Picciocchi A, Fares MC, Rosetto ME, Mantini G, Morganti AG, Barbaro B, Cogliandolo S, Nuzzo G, Tedesco M, Ambesi-Impiombato F, Cosimelli $\mathrm{M}$, Rotman M. Ten years of preoperative chemoradiation for extraperitoneal T3 rectal cancer: acute toxicity, tumor response, and sphincter preservation in three consecutive studies. Int J Radiat Oncol Biol Phys 2001; 51: 371-383

37 Pucciarelli S, Toppan P, Friso ML, Russo V, Pasetto L, Urso E, Marino F, Ambrosi A, Lise M. Complete pathologic response following preoperative chemoradiation therapy for middle to lower rectal cancer is not a prognostic factor for a better outcome. Dis Colon Rectum 2004; 47: 1798-1807

38 Ryan R, Gibbons D, Hyland JM, Treanor D, White A, Mulcahy HE, O'Donoghue DP, Moriarty M, Fennelly D, Sheahan K. Pathological response following long-course neoadjuvant chemoradiotherapy for locally advanced rectal cancer. Histopathology 2005; 47: 141-146

39 Wheeler JM, Dodds E, Warren BF, Cunningham C, George BD, Jones AC, Mortensen NJ. Preoperative chemoradiotherapy and total mesorectal excision surgery for locally advanced rectal cancer: correlation with rectal cancer regression grade. Dis Colon Rectum 2004; 47: 2025-2031

40 Rödel C, Martus P, Papadoupolos T, Füzesi L, Klimpfinger M, Fietkau R, Liersch T, Hohenberger W, Raab R, Sauer R, Wittekind C. Prognostic significance of tumor regression after preoperative chemoradiotherapy for rectal cancer. J Clin Oncol 2005; 23: 8688-8696

41 Kim DW, Kim DY, Kim TH, Jung KH, Chang HJ, Sohn DK, Lim SB, Choi HS, Jeong SY, Park JG. Is T classification still correlated with lymph node status after preoperative chemoradiotherapy for rectal cancer? Cancer 2006; 106: 1694-1700

42 Compton CC. Updated protocol for the examination of specimens from patients with carcinomas of the colon and rectum, excluding carcinoid tumors, lymphomas, sarcomas, and tumors of the vermiform appendix: a basis for checklists. Cancer Committee. Arch Pathol Lab Med 2000; 124: 1016-1025

43 Compton CC, Fielding LP, Burgart LJ, Conley B, Cooper HS, Hamilton SR, Hammond ME, Henson DE, Hutter RV, Nagle RB, Nielsen ML, Sargent DJ, Taylor CR, Welton M, Willett C. Prognostic factors in colorectal cancer. College of American Pathologists Consensus Statement 1999. Arch Pathol Lab Med 2000; 124: 979-994

44 Nagtegaal ID, Marijnen CA, Kranenbarg EK, Mulder-Stapel A, Hermans J, van de Velde CJ, van Krieken JH. Short-term preoperative radiotherapy interferes with the determination of pathological parameters in rectal cancer. J Pathol 2002; 197: 20-27

45 Marijnen CA, Nagtegaal ID, Klein Kranenbarg E, Hermans J, van de Velde CJ, Leer JW, van Krieken JH. No downstaging after short-term preoperative radiotherapy in rectal cancer pa- tients. J Clin Oncol 2001; 19: 1976-1984

46 García-Aguilar J, Hernandez de Anda E, Sirivongs P, Lee $\mathrm{SH}$, Madoff RD, Rothenberger DA. A pathologic complete response to preoperative chemoradiation is associated with lower local recurrence and improved survival in rectal cancer patients treated by mesorectal excision. Dis Colon Rectum 2003; 46: 298-304

47 Meade PG, Blatchford GJ, Thorson AG, Christensen MA, Ternent CA. Preoperative chemoradiation downstages locally advanced ultrasound-staged rectal cancer. Am J Surg 1995; 170: 609-612; discussion 612-613

48 Kaminsky-Forrett MC, Conroy T, Luporsi E, Peiffert D, Lapeyre M, Boissel P, Guillemin F, Bey P. Prognostic implications of downstaging following preoperative radiation therapy for operable T3-T4 rectal cancer. Int J Radiat Oncol Biol Phys 1998; 42: 935-941

49 Janjan NA, Khoo VS, Abbruzzese J, Pazdur R, Dubrow R, Cleary KR, Allen PK, Lynch PM, Glober G, Wolff R, Rich TA, Skibber J. Tumor downstaging and sphincter preservation with preoperative chemoradiation in locally advanced rectal cancer: the M. D. Anderson Cancer Center experience. Int J Radiat Oncol Biol Phys 1999; 44: 1027-1038

50 Read TE, Andujar JE, Caushaj PF, Johnston DR, Dietz DW, Myerson RJ, Fleshman JW, Birnbaum EH, Mutch MG, Kodner IJ. Neoadjuvant therapy for rectal cancer: histologic response of the primary tumor predicts nodal status. Dis Colon Rectum 2004; 47: 825-831

51 Moutardier V, Tardat E, Giovannini M, Lelong B, Guiramand J, Magnin V, Houvenaeghel G, Delpero JR. Long-term results of preoperative radiotherapy for 113 cases of UT3 and UT4 rectal cancer: a need for long-term follow-up. Dis Colon Rectum 2003; 46: 1194-1199

52 Lopez-Crapez E, Bibeau F, Thézenas S, Ychou M, SimonyLafontaine J, Thirion A, Azria D, Grenier J, Senesse P. p53 status and response to radiotherapy in rectal cancer: a prospective multilevel analysis. Br J Cancer 2005; 92: 2114-2121

53 Graf W, Dahlberg M, Osman MM, Holmberg L, Pählman L, Glimelius B. Short-term preoperative radiotherapy results in down-staging of rectal cancer: a study of 1316 patients. Radiother Oncol 1997; 43: 133-137

54 Wijesuriya RE, Deen KI, Hewavisenthi J, Balawardana J, Perera M. Neoadjuvant therapy for rectal cancer down-stages the tumor but reduces lymph node harvest significantly. Surg Today 2005; 35: 442-445

55 Joseph NE, Sigurdson ER, Hanlon AL, Wang H, Mayer RJ, MacDonald JS, Catalano PJ, Haller DG. Accuracy of determining nodal negativity in colorectal cancer on the basis of the number of nodes retrieved on resection. Ann Surg Oncol 2003; 10: 213-218

56 Bilchik A. More (nodes) + more (analysis) = less (mortality) challenging the therapeutic equation for early-stage colon cancer. Ann Surg Oncol 2003; 10: 203-205

57 Brown CL, Ternent CA, Thorson AG, Christensen MA, Blatchford GJ, Shashidharan M, Haynatzki GR. Response to preoperative chemoradiation in stage II and III rectal cancer. Dis Colon Rectum 2003; 46: 1189-1193

58 Zmora O, Dasilva GM, Gurland B, Pfeffer R, Koller M, Nogueras JJ, Wexner SD. Does rectal wall tumor eradication with preoperative chemoradiation permit a change in the operative strategy? Dis Colon Rectum 2004; 47: 1607-1612

59 Guillem JG, Chessin DB, Cohen AM, Shia J, Mazumdar M, Enker W, Paty PB, Weiser MR, Klimstra D, Saltz L, Minsky $\mathrm{BD}$, Wong WD. Long-term oncologic outcome following preoperative combined modality therapy and total mesorectal excision of locally advanced rectal cancer. Ann Surg 2005; 241: 829-836; discussion 836-838

60 Mohiuddin M, Regine WF, John WJ, Hagihara PF, McGrath PC, Kenady DE, Marks G. Preoperative chemoradiation in fixed distal rectal cancer: dose time factors for pathological complete response. Int J Radiat Oncol Biol Phys 2000; 46: 883-888

61 Hiotis SP, Weber SM, Cohen AM, Minsky BD, Paty PB, Guillem JG, Wagman R, Saltz LB, Wong WD. Assessing the 
predictive value of clinical complete response to neoadjuvant therapy for rectal cancer: an analysis of 488 patients. J Am Coll Surg 2002; 194: 131-135; discussion 135-136

62 Miller AB, Hoogstraten B, Staquet M, Winkler A. Reporting results of cancer treatment. Cancer 1981; 47: 207-214

63 Francois Y, Nemoz CJ, Baulieux J, Vignal J, Grandjean JP, Partensky C, Souquet JC, Adeleine P, Gerard JP. Influence of the interval between preoperative radiation therapy and surgery on downstaging and on the rate of sphincter-sparing surgery for rectal cancer: the Lyon R90-01 randomized trial. J Clin Oncol 1999; 17: 2396

64 Bujko K, Nowacki MP, Nasierowska-Guttmejer A, Kepka L, Winkler-Spytkowska B, Suwiński R, Oledzki J, Stryczyńska G, Wieczorek A, Serkies K, Rogowska D, Tokar P. Prediction of mesorectal nodal metastases after chemoradiation for rectal cancer: results of a randomised trial: implication for subsequent local excision. Radiother Oncol 2005; 76: 234-240

65 Kim CJ, Yeatman TJ, Coppola D, Trotti A, Williams B, Barthel JS, Dinwoodie W, Karl RC, Marcet J. Local excision of T2 and T3 rectal cancers after downstaging chemoradiation. Ann Surg 2001; 234: 352-358; discussion 358-359

66 Schell SR, Zlotecki RA, Mendenhall WM, Marsh RW, Vauthey JN, Copeland EM. Transanal excision of locally advanced rectal cancers downstaged using neoadjuvant chemoradiotherapy. J Am Coll Surg 2002; 194: 584-590; discussion 590-591

67 Bujko K, Nowacki MP, Nasierowska-Guttmejer A, Michalski W, Bebenek M, Pudełko M, Kryj M, Oledzki J, Szmeja J, Słuszniak J, Serkies K, Kładny J, Pamucka M, Kukołowicz P. Sphincter preservation following preoperative radiotherapy for rectal cancer: report of a randomised trial comparing short-term radiotherapy vs. conventionally fractionated radiochemotherapy. Radiother Oncol 2004; 72: 15-24

68 Hahnloser D, Wolff BG, Larson DW, Ping J, Nivatvongs S. Im- mediate radical resection after local excision of rectal cancer: an oncologic compromise? Dis Colon Rectum 2005; 48: 429-437

69 Kahn H, Alexander A, Rakinic J, Nagle D, Fry R. Preoperative staging of irradiated rectal cancers using digital rectal examination, computed tomography, endorectal ultrasound, and magnetic resonance imaging does not accurately predict T0,N0 pathology. Dis Colon Rectum 1997; 40: 140-144

70 Gavioli M, Bagni A, Piccagli I, Fundaro S, Natalini G. Usefulness of endorectal ultrasound after preoperative radiotherapy in rectal cancer: comparison between sonographic and histopathologic changes. Dis Colon Rectum 2000; 43: 1075-1083

71 Kim YH, Kim DY, Kim TH, Jung KH, Chang HJ, Jeong SY, Sohn DK, Choi HS, Ahn JB, Kim DH, Lim SB, Lee JS, Park JG. Usefulness of magnetic resonance volumetric evaluation in predicting response to preoperative concurrent chemoradiotherapy in patients with resectable rectal cancer. Int J Radiat Oncol Biol Phys 2005; 62: 761-768

72 Katz MS, Minsky BD, Saltz LB, Riedel E, Chessin DB, Guillem JG. Association of statin use with a pathologic complete response to neoadjuvant chemoradiation for rectal cancer. Int $J$ Radiat Oncol Biol Phys 2005; 62: 1363-1370

73 Henri M, Latulippe JF, Heyen F, Dubé S. Complete pathologic response after chemoradiation for rectal cancer. Dis Colon Rectum 2005; 48: 1097-1098; author reply 1098

74 Nagtegaal I, Gaspar C, Marijnen C, Van De Velde C, Fodde R, Van Krieken H. Morphological changes in tumour type after radiotherapy are accompanied by changes in gene expression profile but not in clinical behaviour. J Pathol 2004; 204: 183-192

75 Suzuki T, Sadahiro S, Fukasawa M, Ishikawa K, Kamijo A Yasuda S, Makuuchi H, Ohizumi Y, Murayama C. Predictive factors of tumor shrinkage and histological regression in patients who received preoperative radiotherapy for rectal cancer. Jpn J Clin Oncol 2004; 34: 740-746

S- Editor Wang GP $\quad$ L- Editor Alpini GD $\quad$ E- Editor Ma WH 